Original Research Paper

\title{
Antimicrobial Susceptibility of Community Acquired Escherichia coli in Urinary Tract Infections (UTI) in Benin for Eleven Years (2005-2015)
}

\author{
${ }^{\text {a,e }}$ Tchiakpe Edmond, ${ }^{\mathrm{i}}$ Laurence Carine Yehouenou, ${ }^{\mathrm{h}}$ Zahra Fall Malick, ${ }^{\mathrm{c}}$ Kpangon Amadohoué Arsène, \\ ${ }^{\mathrm{a}}$ Keke Kpemahouton René, ${ }^{\mathrm{d}}$ Abou Abdallah Malick Diouara, ${ }^{\mathrm{g}}$ Issa Tondé, ${ }^{\mathrm{b}}$ Honoré Sourou Bankolé, \\ ${ }^{\mathrm{f}}$ Bekou Kossi Wilfried, ${ }^{\mathrm{f}}$ Esse Atchéni Marius, ${ }^{\mathrm{d}}$ Halimatou Diop Ndiaye and ${ }^{\mathrm{d}}$ Coumba Touré Kane \\ ${ }^{a}$ National Laboratory Fighting Against AIDS, National Direction of Health, Health Ministry, 04PO Box 378 Cotonou, Benin \\ ${ }^{b}$ Department of Human Biology, Research Laboratory in Applied Biology, \\ Polytechnic, School of Abomey-Calavi, University of Abomey-Calavi, 01 PO Box 2009, Cotonou, Benin \\ ${ }^{c}$ Department of Medecine, Internal Medicine Service of Hospital Center, University Parakou, PO Box: 02 Parakou, Bénin \\ ${ }^{d}$ Department of Medecine Laboratory of Bacteriology and Virology, \\ University Cheikh Anta Diop, PO Box 7325, 30 Avenue Pasteur, Dakar, Senegal \\ ${ }^{e}$ Department of Pharmacy, Drugs and Diagnostic Investigation, \\ National Laboratory of Health Ministry, 04 PO Box 378, Cotonou, Bénin \\ ${ }^{f}$ Department of Medecine, National Laboratory Fighting Against Tuberculosis, 01 PO Box 321 Cotonou, Benin \\ ${ }^{g}$ Department of Medecine, Medical Analysis Laboratory of Pediatric, \\ University Hospital Charles De Gaule of Ouagadougou, Burkina Faso \\ ${ }^{h}$ Department of Medecine, National Hepato-Virology Institute, Medicine Faculty of Mauritanie, Mauritanie \\ ${ }^{i}$ Department of Medecin, National Laboratory Fighting Against Tuberculosis; 01 POBox 321 Cotonou, Benin
}

Corresponding Author:

Tchiakpe Edmond

National Laboratory Fighting

Against AIDS, National

Direction of Health, Health

Ministry, 04PO Box 378

Cotonou, Benin

E-mail: edtchi@yahoo.fr

\begin{abstract}
Antimicrobial resistance became a growing public health problem in the world and Escherichia coli (E. coli) appeared as one of nine bacteria commonly causing infections in community and hospitals. It prevalence and it resistance to antibiotics were evaluated in Benin throughout an eleven year period. In this retrospective study, routine urine samples from patients collected at the National Laboratory (NL) of Health Ministry during the period 2005-2015 were analyzed. Samples higher than $103 \mathrm{CFU} / \mathrm{mL}$ bacterial growth were considered positive and for these cases, the bacteria were identified and Antimicrobial Susceptibility Test (AST) was performed. From the 4467 samples analyzed, 1455 (32.6\%) were positive with E. coli preponderance $(38.3 \%)$ of all isolated germs and $(58.5 \%)$ of enterobacteriaceae. Most of the isolates were susceptibility to netilmicin (80\%), gentamycin (93\%), chloramphenicol $(70 \%)$, pipemidic acid $(60 \%)$, nalidixic acid $(75 \%)$, ciprofloxacin $(75 \%)$, amoxicillin/clavulanic acid $(80 \%)$ and nitrofurantoin $(100 \%)$. Susceptibility rates increased for cefotaxim $(78-100 \%)$, ceftriaxon (71-100\%) and aztreonam (67-100\%). Resistances were observed for minocyclin $(70 \%)$, Trimethoprim/Sulfamethoxazole (TMP-SMX) $(60 \%)$, ampicillin (67\%), amoxicillin (75\%), carbenicillin (86\%), cephalothin and cephalexin (50 and $80 \%$ respectively). The use of drugs such as minocyclin, ampicillin, amoxicillin, carbenicillin, cephalothin, cephalexin and trimethoprim/sulfamethoxazole does not seem appropriate for empirical treatment of UTI in Benin.
\end{abstract}

Keywords: Community, Urinary Tract Infections, Escherichia coli, Antimicrobial Effectiveness, Benin

\section{Introduction}

Antimicrobial resistance had become a growing public health problem in the world and $E$. coli appeared as one of nine bacteria commonly causing infections in community and hospitals (WHO, 2014). Worldwide, $E$. coli remains the most encountered pathogen among those implicated in community acquired urinary tract infection (Jean-Marie et al., 2007). With (46.4-74.2\%) of global representation (Inês et al., 2013), it's the first
Science

Publications
(C) 2017 Tchiakpe Edmond, Laurence Carine Yehouenou, Zahra Fall Malick, Kpangon Amadohoué Arsène, Kèkè Kpemahouton René, Abou Abdallah Malick Diouara, Issa Tondé, Honoré Sourou Bankolé, Békou Kossi Wilfried, Esse Atchéni Marius, Halimatou Diop N'diaye and Coumba Touré Kan. This open access article is distributed under a Creative 
strains isolated in children between 2 to 5 years of age followed by Klebsiella, Proteus and Pseudomonas (Rajiv et al., 2013). In a recent study done in 2012 at Ngaoundere in Cameroon focused on community acquired infection, Carine et al. (2012) found that $66.7 \%$ of $E$. coli was mostly Extended-spectrum betalactamase producers in the samples of stools. It is well known the proximity between anal cavity and urinary tract in women. Urinary Tract Infections (UTI) is the most commonly diagnosed infections in communities which are often treated with different antibiotics. Some studies have reported an increasing resistance rate to antibiotics such as amoxicillin, amino penicillin, trimetropimsulfamethoxazole and others reducing therapeutic possibilities (Gupta et al., 1999; Kahlmeter, 2003a).

A study conducted in Benin have shown, that the beta lactam antibiotics were the most prescribed and represented $44.4 \%$ of prescriptions, followed, in order of imidazole, quinolones, aminoglycosides, sulfonamides, macrolides and related, cyclins and phenicol (Dissou et al., 2009). However, in Benin, few documentations exist in antimicrobial resistance of uropathogen isolated in UTI. The aim of this study was to describe the bacterial profile of UTI and antimicrobial susceptibility of $E$. coli strains isolated from the urine cultures of Benin patients in National Laboratory (NL) of Heath Ministry over 11 year period.

\section{Methods}

Routine urine samples data were collected from patients in Cotonou between $1^{\text {st }}$ January 2005 and $31^{\text {st }}$ December 2015 period. This study was approved by the Research Ethics Committee for Applied Biomedical Sciences (CERISBA) of Abomey Calavi University of Benin. A retrospective cross sectional study was conducted in NL where urine samples were analyzed. For each patient we extracted from the laboratory records, year, age, sex, early urine culture results, identification of the bacterial strain responsible of UTI and the corresponding Antimicrobial Susceptibility Test (AST) results.

The statistical test EpiData 3.1 was used to check-in results and EpiData Analysis V2.2.2.182 for data analysis. Data were expressed an absolute values and percentage. The chi-2 test was used to compare proportions. To be significant, the $\mathrm{p}$ value should be less than 0.05 .

\section{Results}

Overall 4467 urine cultures were performed during 2005-2015 period. The rate of positive cultures was $32.6 \%$ (1455/4467) of which 1470 bacteria have been isolated. Characteristics of patients included in the study are shown in Table 1 . Mean age and sex ratio $(\mathrm{M} / \mathrm{F})$ of study population were 30.5 years [ $95 \%$ Confidence Interval (CI) 30.01-30.98] and 0.5. Frequencies and distribution of isolated uropathogenic bacteria during the eleven study years were summarized in Table 2. The enterobacteriaceae proportion was $65.5 \% \quad(963 / 1470)$ with $E$ coli preponderance which represented $38.3 \%(563 / 1470)$ of all isolated bacteria and 58.5\% (563/963) of enterobacteriaceae. The others most represented isolated bacteria were Klebsiella pneumoniae 23.4\% (344/1470), Staphylococcus aureus 16.0\% (235/1470), Staphylococcus spp 7.6\% (111/1470), Staphylococcus dore 3.7\% (54/1470).

The Fig. 1 shows the susceptibility rates of $E$. coli for aminoglycosides, tetracycline, phenicol, quinolones, sulfonamides+associations, penicillin, cephalosporin, aztreonam and nitrofurantoin.

Regarding aminoglycosides, we observed susceptibility increase of $E$. coli to netilmicin $(10 \mu \mathrm{g})(80$ to $100 \%)$ on three use years. During the 11 study years, the maximum susceptibility rate to gentamycin $(30 \mu \mathrm{g})$ was $93.3 \%$.

Since $2007, E$. coli susceptibility to tetracyclin (30 $\mu \mathrm{g})$ decrease to $12 \%$ at 2015 . Concerning minocyclin (30 $\mu \mathrm{g}$ ), on three use years, his susceptibility rate was $30 \%$.

Among phenicol, chloramphenicol $(30 \mu \mathrm{g})$ was one used during the first ten years. E. coli susceptibility to this drug varied between (38 to 70\%) until 2014 .

Among quinolones, pipemidic acid (20 ug) was tested during three years (2005-2007) with $E$. coli susceptibility rate not exceeded $60 \%$. The others same class antibiotics used (2005-2015) were nalidixic acid (30 ug) while the maximum E. coli susceptibility rate was $75 \%$ and ciprofloxacin (10 ug) while susceptibility rate increased and reached $100 \%$ at 2010 and decreased to $75 \%$ at 2015 .

For sulfonamides+associations (25 ug) class, E. coli susceptibility to Trimethoprim/Sulfamethoxazole (TMPSMX) not exceeded 40\% (2005-2011). This susceptibility decrease from 2011 to 2015 (at $0 \%$ ). Four penicillin class of antibiotics have been tested. Ampicillin (30 ug) has been used during two years (2005 and 2014) and E. coli susceptibility rate around $33 \%$. During the 11 study years and the same class, amoxicillin ( $25 \mathrm{ug}$ ) was less active to $E$. coli while susceptibility rate not exceeded $25 \%$. As for Amoxicillin/Clavulanic acid (AMC) (30 ug), the most tested antibiotic in this class, effectiveness was observed until 2009 (80\%). But from this year, a loss effectiveness was observed until 2015 (62\%). On three use years, carbenicillin (100 ug) was less active to E. coli while susceptibility rate not exceeded $14 \%$.

Table 1. Characteristics of patients included in the study

\begin{tabular}{ll}
\hline Characteristic & All patients $(\mathrm{N}=4467)$ \\
\hline Sex & $1576(35.28 \%)$ \\
Male & $2891(64.72 \%)$ \\
Female & \\
Age (years) & 1 \\
Minimum & 95 \\
Maximum & 30.50 \\
Mean & \\
Cultures & $1455(32.57 \%)$ \\
Positive & $3012(67.43 \%)$ \\
Negative &
\end{tabular}


Tchiakpe Edmond et al. / American Journal of Infectious Diseases 2017, 13 (2): 21.27 DOI: 10.3844/ajidsp.2017.21.27

Table 2. Percentage and distribution of isolated uropathogenic germs during the eleven study years

\begin{tabular}{|c|c|c|c|c|c|c|c|c|c|c|c|c|}
\hline Bacteria & $\mathrm{n}(\%)$ & 2005 & 2006 & 2007 & 2008 & 2009 & 2010 & 2011 & 2012 & 2013 & 2014 & 2015 \\
\hline Escherichia coli & $563(38.3)$ & 119 & 118 & 67 & 28 & 34 & 35 & 16 & 45 & 53 & 40 & 8 \\
\hline Klebsiella pneumoniae & $344(23.4)$ & 49 & 40 & 29 & 29 & 32 & 25 & 25 & 48 & 33 & 22 & 12 \\
\hline Staphylococcus aureus & $235(16.0)$ & 38 & 47 & 28 & 10 & 26 & 10 & 13 & 22 & 21 & 17 & 3 \\
\hline Staphylococcus spp & $136(9.7)$ & 0 & 8 & 8 & 7 & 10 & 7 & 11 & 24 & 23 & 29 & 9 \\
\hline Staphylococcus dore & $54(3.7)$ & 50 & 2 & 1 & 0 & 0 & 0 & 0 & 1 & 0 & 0 & 0 \\
\hline Streptococcus $\beta$ hemolytique & $36(2.4)$ & 2 & 5 & 4 & 5 & 2 & 4 & 2 & 3 & 2 & 7 & 0 \\
\hline Pseudomonas spp & $23(1,2)$ & 8 & 5 & 2 & 1 & 1 & 2 & 0 & 2 & 1 & 1 & 0 \\
\hline Staphylococcus citrin & $13(0.9)$ & 12 & 0 & 1 & 0 & 0 & 0 & 0 & 0 & 0 & 0 & 0 \\
\hline Pseudomonas aeruginosa & $13(0.9)$ & 0 & 3 & 3 & 0 & 1 & 2 & 0 & 0 & 1 & 2 & 1 \\
\hline Klebsiella oxytoca & $13(0.9)$ & 0 & 0 & 2 & 1 & 3 & 2 & 1 & 3 & 1 & 0 & 0 \\
\hline Citrobacter spp & $10(0.7)$ & 1 & 3 & 2 & 0 & 0 & 1 & 0 & 2 & 1 & 0 & 0 \\
\hline Proteus mirabilis & $7(0.5)$ & 1 & 1 & 2 & 1 & 0 & 0 & 1 & 0 & 1 & 0 & 0 \\
\hline Candida albicans & $4(0.3)$ & 0 & 1 & 2 & 1 & 0 & 0 & 0 & 0 & 0 & 0 & 0 \\
\hline Proteus vulgaris & $4(0.3)$ & 2 & 0 & 0 & 1 & 0 & 0 & 0 & 0 & 1 & 0 & 0 \\
\hline Levinea & $4(0.3)$ & 3 & 0 & 0 & 1 & 0 & 0 & 0 & 0 & 0 & 0 & 0 \\
\hline Proteus morganii & $3(0.2)$ & 2 & 0 & 0 & 1 & 0 & 0 & 0 & 0 & 0 & 0 & 0 \\
\hline Bacille pyocyanique & $2(0.1)$ & 2 & 0 & 0 & 0 & 0 & 0 & 0 & 0 & 0 & 0 & 0 \\
\hline Edwardsiella & $1(0.1)$ & 0 & 0 & 0 & 0 & 0 & 0 & 0 & 1 & 0 & 0 & 0 \\
\hline Arizona rhinochromatis & $1(0.1)$ & 0 & 0 & 1 & 0 & 0 & 0 & 0 & 0 & 0 & 0 & 0 \\
\hline Listeria monocystogene & $1(0.1)$ & 0 & 1 & 0 & 0 & 0 & 0 & 0 & 0 & 0 & 0 & 0 \\
\hline Proteus rettgeu & $1(0.1)$ & 0 & 0 & 0 & 0 & 1 & 0 & 0 & 0 & 0 & 0 & 0 \\
\hline Levinea malonalica & $1(0.1)$ & 0 & 0 & 0 & 0 & 1 & 0 & 0 & 0 & 0 & 0 & 0 \\
\hline Streptococcus faecalis & $1(0.1)$ & 0 & 0 & 0 & 0 & 1 & 0 & 0 & 0 & 0 & 0 & 0 \\
\hline Total & $1470(100,0)$ & 289 & 234 & 152 & 86 & 112 & 88 & 69 & 151 & 138 & 118 & 33 \\
\hline
\end{tabular}
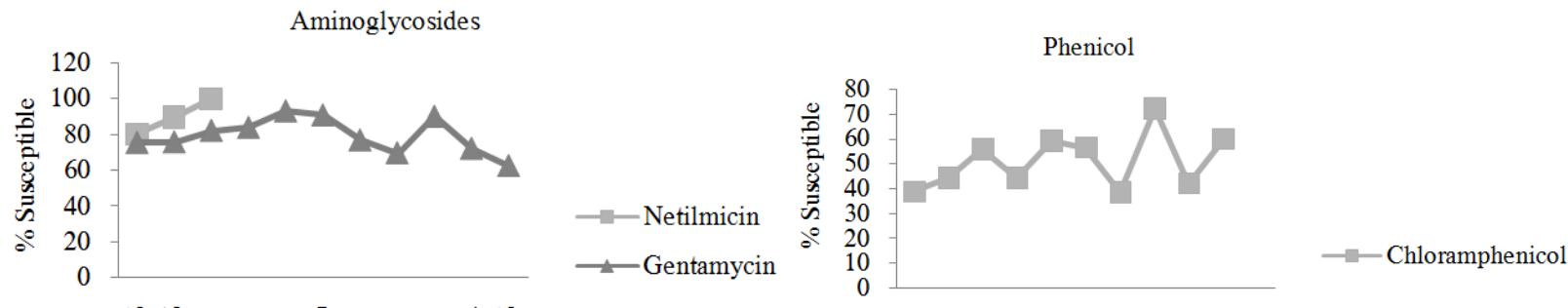

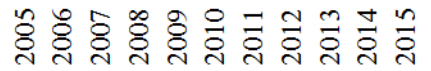

Years

Sulfonamides + Associations

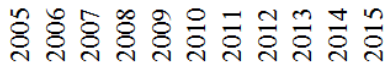

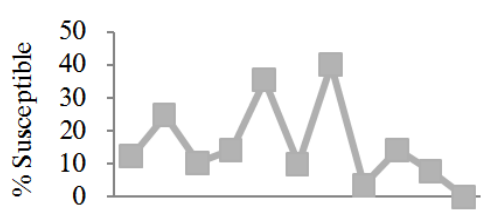

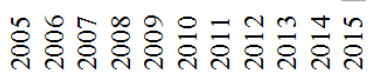

Years

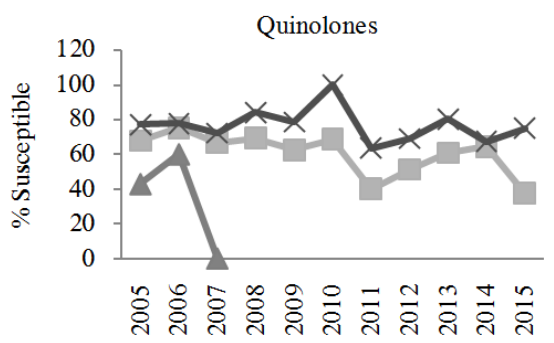

Years $\longrightarrow$ - Nalidixic acid

$\longrightarrow$ Pipemidic acid $\rightarrow$ Ciprofloxacin

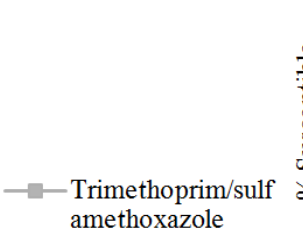

amethoxazole

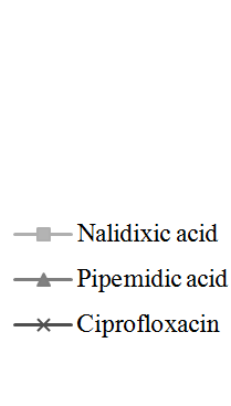

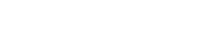

Years

Tetracyclin

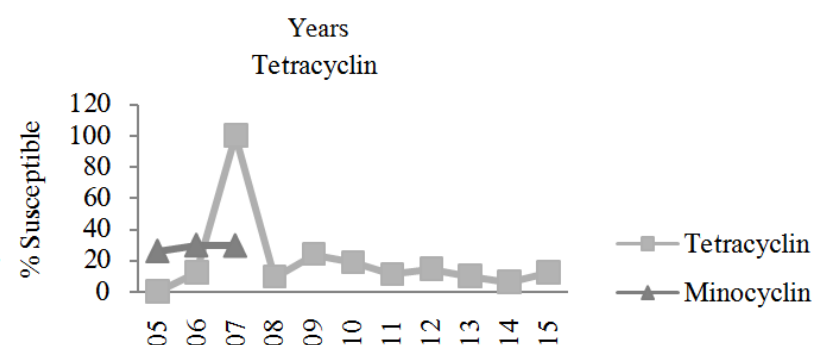

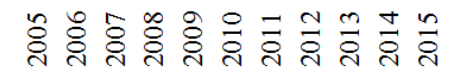

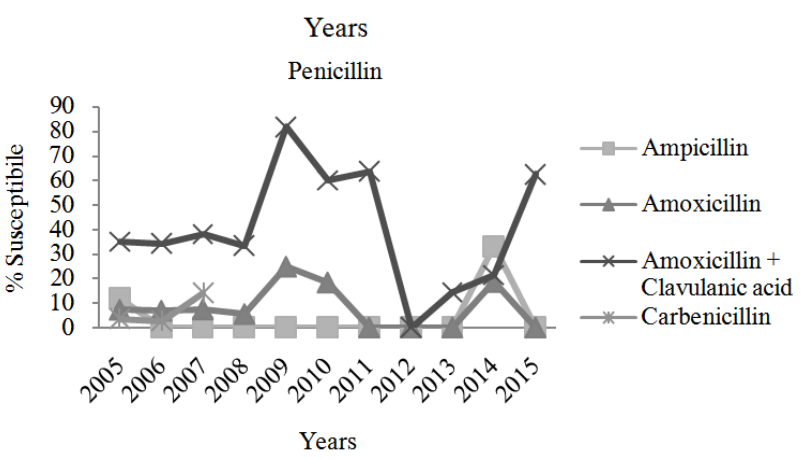




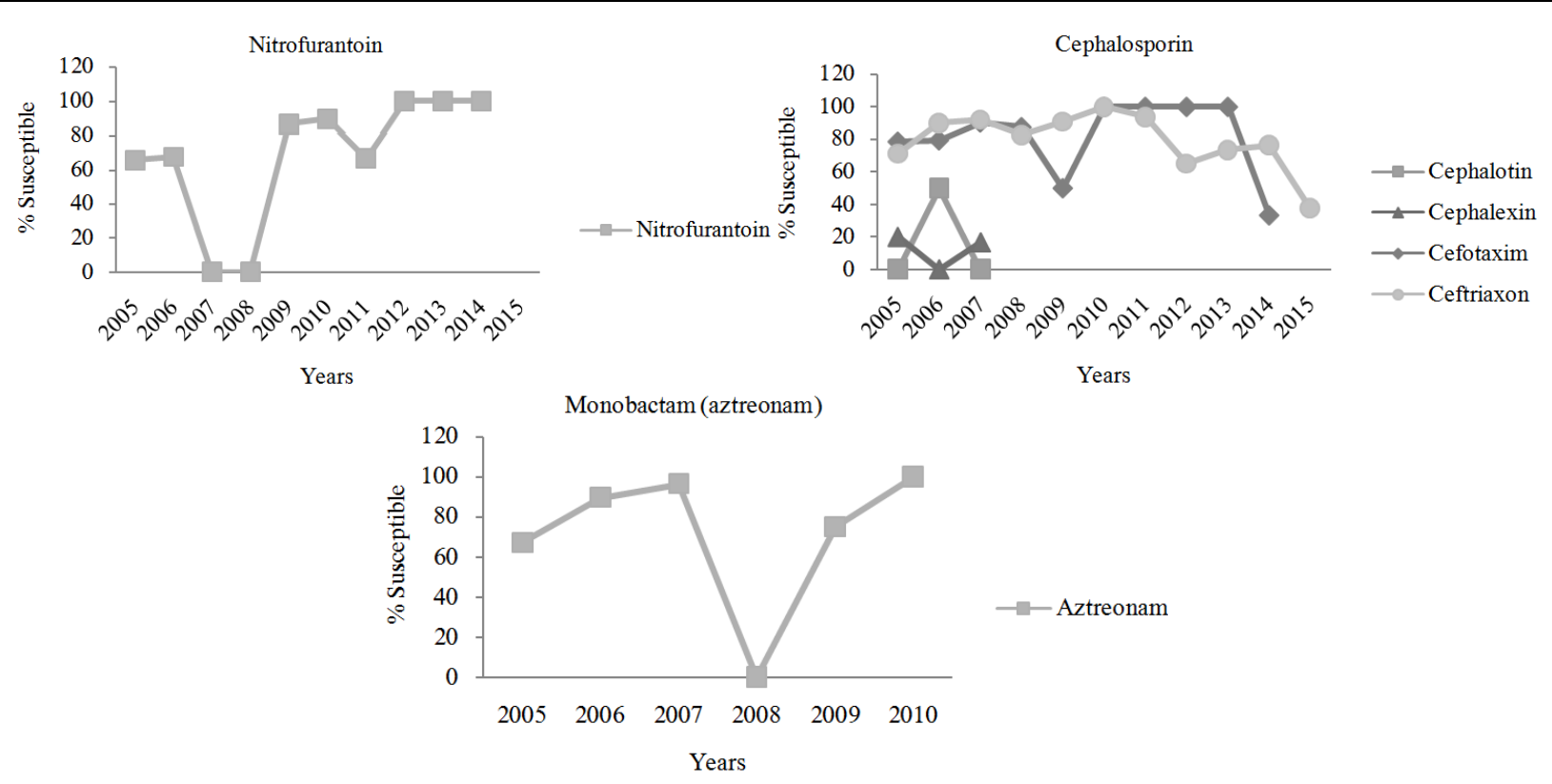

Fig. 1. Susceptibility rates of E. coli for aminoglycosides, tetracyclin, phenicol, quinolones, sulfonamides+associations, penicillin, cephalosporin, aztreonam and nitrofurantoin

About cephalosporin, four antibiotics were tested: cephalothin $(30 \mathrm{ug})$, cephalexin $(30 \mathrm{ug})$, cefotaxim $(30 \mathrm{ug})$, ceftriaxone $(30 \mathrm{ug})$. Cephalothin and cephalexin have been tested three years each. E. coli susceptibility rate to these drugs was $50 \%$ and $20 \%$ respectively. Cefotaxim and ceftriaxon were very effectiveness and were mainly tested of antibiotics. Their effectiveness rate to $E$. coli reached $100 \%$ to 2010. From this year, these effectiveness have loss until 2015 with $33.3 \%$ and $37.5 \%$ rate respectively. $E$. coli developed resistance to cephalothin and cephalexin (50\% and $80 \%$ respectively).

Aztreonam (30 ug) tested during six years showed $100 \%$ rate effectiveness to $E$. coli. Following a decrease in 2008, a continuous increase in susceptibility rates was observed until $2010(100 \%)$.

Among nitrofurans tested, nitrofurantoin (300 ug) using till 2014, showed a good effectiveness with $100 \%$ rate.

\section{Discussion}

E. coli appeared as the most frequent bacteria in UTI representing 38.3\% (563/1470) of all isolated bacteria and $58.5 \%$ (563/963) of enterobacteriaceae. The second major finding in our study was $E$. coli susceptibility to antibiotics.

In Benin, UTI were major causes of antibiotics prescribing among adults and adolescences (Dissou et al., 2009). The lack of national recommandations involve their bad utilization (Dissou et al., 2009). In fact, Benin is West Africa country where a lot of counterfeit drug are circulating. A Pharmaceutical desposit drug is in Cotonou at Dantokpa market. Thus, the population supply drug and taking care by self-medication. In addition, due to their results quality, the NL received widely patients for uroculture analyzes. This should explain the $32.6 \%$ rate positive uroculture observed in this study. This rate was two fold higher that observed in Senegal (Diop-Ndiaye et al., 2014) and Portugal (Inês et al., 2013). The major bacteria isolated in those studies was E. coli as in our study (38.3\%) which the virulence factors are specific properties. Those specificity confer on the bacterium the ability to adhere to the urinary tract and invade the host tissues causing injury (Moura et al., 2009). This study shows a proportion of E. coli $(38.3 \%, 563 / 1470)$, significantly lower than that observed by Nisel et al. (2016) $(67 \%, 8975 / 13281)$.

Antibiotics resistance has increased in alarming proportions (WHO, 2001a; 2001b). Thus, their effectiveness for UTI treatment became quite limited (Temesgen et al., 2015). In our study, among amino glycosides, netilmicin showed susceptibility above $80 \%$. This rate was similar those observed in Portugal and Bangui (98.7 and 96\% respectively) (Hadiza et al., 2003; Inês et al., 2013). As for gentamycin, frontline antibiotic in the treatment of gram negative bacteria, its efficacy was $93 \%$ equal almost those observed in India, Senegal and Bangui (83.6, 93.8, 94\% respectively) (Hadiza et al., 2003; Jean-Marie et al., 2007; Rajiv et al., 2013).

As for tetracycline, from 2007 year, the resistance rate around $76 \%$. The loss effectiveness was very 
alarming and this antibiotic should not be prescribed against UTI. At Pakistan, a similar resistance rate of $E$. coli to tetracyclin was observed in $70 \%$ (Ahmad et al., 2015). Minocyclin in the first three years showed effectiveness around 30\% while a study conducted in China reported $92.1 \%$ of susceptibility by (Haihong et al., 2015).

The maximum efficacy rate of chloramphenicol to E. coli was $60 \%$. Behailu et al. (2016) reported in Dil Chora Referral Hospital, Dire Dawa, Eastern Ethiopia an effectiveness rate of $77.8 \%$ in study conducted among pregnant women attending at antenatal clinic (Behailu et al., 2016).

Over 11 year, nalidixic acid had maximum efficacy rate at $75 \%$. This rate was lower than observed at Bangui (90\%) (Hadiza et al., 2003). However, none difference has been observed between the rate that of Dakar $(76.1 \%)(\mathrm{p}=0.889)$ (Jean-Marie et al., 2007). This antibiotic was the first among quinolone used only for the therapy of gram-negative UTI, because it has ability to penetrate the tissues (Moura et al., 2009). Of high susceptibility until 2010, the loss effectiveness of ciprofloxacin should be explain by its large use. In fact, ciprofloxacin can be used in UTI patients with allergies to others drug or in old age patients with recurrent infections and in diabetics (Eom et al., 2002; Schilling et al., 2002; Killgore et al., 2004). Nevertheless, the $75 \%$ susceptibility rate of E. coli observed in 2015 was not significant ( $\mathrm{p}=$ 0.811) that observed in Dakar (Jean-Marie et al., 2007).

Until 2011, forty percent of $E$. coli were susceptibility to TMP-SMX. This antibiotic was also called co-trimoxazole. Some variable susceptibility rates were observed in several studies: $(70.9-71.8 \%)$ in Northern Israel (Wasseem et al., 2007), 31.9 and 40\% at Dakar (Jean-Marie et al., 2007; Diop-Ndiaye et al., 2014), $15 \%$ in Bangui (Hadiza et al., 2003), 35\% to Pakistan (Ahmad et al., 2015). TMP-SMX resistance rates of 25-68\% were also reported in others countries (Urbina et al., 1989; Wylie and Koornhof, 1989). After 2011 year, a total loss of effectiveness was observed with this antibiotic, that should be explained by its no medically in use through its supply by the people in the market.

The effectiveness rates of ampicillin and amoxicillin in our study were $33 \%$ and $25 \%$ respectively. Primarily, resistance to these antibiotics by $\beta$-lactamase producing $E$. coli come from their sub-inhibitory concentrations (Moura et al., 2009). Concerning amoxicillin, some studies conducted at Dakar have shown similar rates as in our study (Jean-Marie et al., 2007; Diop-Ndiaye et al., 2014). As for ampicillin, the study investigated the prevalence of antibiotic resistance in urinary tract infections caused by $E$. coli in children showed $53.4 \%$ of resistance rate (Ashley et al., 2016) while 67\% has been reported in our study and Turkey (Nisel et al., 2016). Of all cases observed in 16 countries in Europe plus Canada, the E. coli resistance to ampicillin was 30\% (Kahlmeter, 2003b).

The amoxicillin/clavulanic acid activity depends on the level of $\beta$-lactamase production by $E$. coli. In our study, it efficacy rate was $82 \%$ during all study period, more one fold higher that reported (59.3\%) by (Alemu et al., 2012). An opposite, Sharan reported $88 \%$ of resistance among children less of 5 years in India (Rajiv et al., 2013).

A resistance rate of $86 \%$ of $E$. coli to carbenicillin was observed in our study, similar that reported $(100 \%)$ on children diarrhea and swim areas on Tigris River in Baghdad city (Israa et al., 2014).

Cephalosporins activity against $E$. coli has increased from first to fourth generation and the new classes were too much. Recently, the number of resistant strains to cephalosporins has increased (Ribeiro et al., 2002). In our study, four antibiotics of this class were tested. Cefotaxim and ceftriaxon showed effectiveness to $100 \%$ during use years. Our results were similar those observed at Dakar (97\%) and Northern Israel (98\%) for each antibiotic respectively (Jean-Marie et al., 2007; Urbina et al., 1989). In contrary, Sharan reported a high resistance for both antibiotics (73.5\% and 73.5\%) among children less of 5 years in India (Rajiv et al., 2013). For cephalosporin for three years, a $50 \%$ susceptibility rate was reported in our study. Wasseem et al (2007) reported effective rate of cephalothin to $E$. coli ranging between $(60 \%-74 \%)$ in Northern Israel. About cephalexin, a high resistance rate of $80 \%$ of this antibiotic to $E$. coli was observed as reported by Datta in India (Datta et al., 2004).

Severe UTI requires appropriate antimicrobial treatment preferably cephalosporins (third generation). But, in patients with an allergy to cephalosporins, aztreonam may be used (Grabe et al., 2015). Our study showed effectiveness of aztreonam to E. coli at $100 \%$. This effectiveness was already seen since 2005 with $67 \%$ rate. In India, Iraj et al. (2015) reported $56.7 \%$ of susceptibility rate among children less than 12 years.

As for nitrofurantoin, a high effectiveness (100\%) observed in our study was similar that observed in Portugal (94\%) (Inês et al., 2013) and india (100\%) (Rajiv et al., 2013). In several studies, nitrofurantoin resistance rates remained at lower levels (Arman et al., 2012; Kahlmeter and Poulsen, 2012; Nisel et al., 2016). The lower rate $(1.3 \%)$ was reported equally in study performed among children used antibiotics in primary care by (Ashley et al., 2016). Because their therapy efficacy has been demonstrated clinically and microbioligically (69\% and 68\%) success respectively (Işıkgöz et al., 2012), nitrofuratoïn should be recommended for ambulantory treatment and the cystitis and pyelonephritis treatment in women even pregnancy (Kalpana et al., 2011). It is a good alternative for uncomplicated UTI treatment when it is dispensed at appropriate dosages and suitable time intervals (Nisel et al., 2016).

Based on our above results mentioned, E. coli susceptibility decreased until $33 \%$ for ampicillin, 30\% for minocyclin, $24 \%$ for tetracyclin and $25 \%$ for 
amoxicillin and fallen to $14 \%$ for carbenicillin, $0 \%$ in 2015 for TMP-SMX, remains around $75 \%$ for ciprofloxacin, while cephalosporin third generation, aztreonam and nitrofurantoin were maintained their effectiveness rate until $100 \%$.

These results are important in medical practice in Benin. We have confirmed now that ampicillin, minocyclin, tetracyclin, amoxicillin, carbenicillin and TMP-SMX couldn't be appropriated for treatment of UTI and that use of quinolone could exposed to resistance in $25 \%$ of cases and that third-generation cephalosporin, aztreonam and nitrofurantoïn are those that offers the highest effectiveness of UTI treatment.

One limitation of this study is the low number of patients per year that did not allow a comparative analysis of the resistance of $E$. coli during the 11 years of study.

\section{Conclusion}

The use of drugs such as minocyclin, ampicillin, amoxicillin, carbenicillin, cephalothin, cephalexin and trimethoprim/sulfamethoxazole does not seem appropriate for empirical treatment of UTI. These findings highlighted the importance in Benin to implement national guideline of antibiotics use and done toward medic and nurse training.

\section{Acknowledgement}

We thank the Ministry of Health through the National Laboratory and the patients and all of the people who directly or indirectly contributed to the successful completion of this study.

\section{Author Contributions}

Tchiakpe Edmond: Study design, data collection, data analysis and writing.

Laurence Carine Yehouenou and Zahra Fall Malick: Study design, writing and reviewing.

Kpangon Amadohoué Arsène and Abou Abdallah Malick Diouara: Study design writing.

Keke Kpemahouton René: Final approval of the version to be submitted.

Issa Tondé: Contributed to the writing.

Honoré Sourou Bankolé and Halimatou Diop Ndiaye: Study design, data collection and writing.

Bekou Kossi Wilfried and Esse Atchéni Marius: Statistical analysis.

Coumba Touré Kane: Study design and data collection.

\section{Conflict of Interest}

There are no conflicts of interest to declare.

\section{References}

Moura, A., A. Nicolau, T. Hooton and J. Azeredo, 2009. Antibiotherapy and pathogenesis of uncomplicated UTI: Difficult relationships. J. Applied Microbiol., 106: 1779-1791.

Ahmad, W., F. Jamshed and W. Ahmad, 2015. Frequency of escherichia coli in patients with community acquired urinary tract infection and their resistance pattern against some commonly used anti bacterials. J. Ayub. Med. Coll Abbottabad, 27: 333-337.

Alemu, A., F. Moges, Y. Shiferaw, K. Tafess and A. Kassu et al., 2012. Bacterial profile and drug susceptibility pattern of urinary tract infection in pregnant women at University of Gondar Teaching Hospital, Northwest Ethiopia. BMC Res. Notes, 25: 197-197.

Arman, D., C. Ağalar, M. Dizbay, T.Ö. Güzel and K.D. Tozlu et al., 2012. Birinci basamak sağlık merkezlerinde toplum kökenli alt üriner sistem enfeksiyonlar1: Etkenler ve antimikrobiyal duyarlılıkları. Mediterr J. Infect. Microb. Antimicrob, 1: 10-18.

Ashley, B., A.D. Hay, I.F. Lane, H.V. Thornton and M. Wootton et al., 2016. Global prevalence of antibiotic resistance in paediatric urinary tract infections caused by Escherichia coli and association with routine use of antibiotics in primary care: Systematic review and meta-analysis. BMJ, 352: 1-11.

Behailu, D., H. Kedir, Z. Teklemariam, F. Weldegebreal and S. Balakrishnan, 2016. Bacterial profile of urinary tract infection and antimicrobial susceptibility pattern among pregnant women attending at antenatal clinic in dil chora referral hospital, Dire Dawa, Eastern Ethiopia. Ther. Clin. Risk Manag., 12: 251-260.

Carine, M.L., C. Meex, J. Gangoué-Piéboji, R. Boreux and M.C. Okomo et al., 2012. Proportion of extended-spectrum B-lactamase-producing Enterobacteriaceae in community setting in Ngaoundere, Cameroon. BMC Infect. Dis., 12: 1-7.

Dissou, A.K.E., A.L. Dossou-Gbété, C.M. Lankpéko, M.N. Paraiso and S.Y. Anagonou, 2009. Evaluation de la prescription des antibiotiques en médecine ambulatoire a Cotonou, Bénin. Bull. Soc. Pathol. Exot., 102: 110-112.

Datta, P., A. Thakur, B. Mishra and V. Gupta, 2004. Prevalence of clinical strains resistant to various beta-lactams in a tertiary care hospital in India. Jpn. J. infect. Dis., 57: 146-149.

Eom, J.S., B.Y. Hwang, J.W. Sohn, M.J. Kim and S.C. Park et al., 2002. Clinical and molecular epidemiology of quinolone-resistant Escherichia coli isolated from urinary tract infection. Microb. Drug Resist., 8: 227-234. 
Gupta, K., D. Scholes and W.E. Stamm, 1999. Increasing prevalence of antimicrobial resistance among uropathogens causing acute uncomplicated cystitis in women. JAMA, 281: 736-738.

Diop-Ndiaye, H., E. Macondo, M. Camara, Y.A. Dia-Padane and H.S. Mikode et al., 2014. Evolution de la résistance aux antibiotiques des Escherichia coli uropathogènes communautaires (2003-2013). URO'ANDRO, 1: 71-78.

Hadiza, H.L., D. Menard and A. Talarmin, 2003. Antimicrobial resistance among uropathogens that cause community-acquired urinary tract infections in Bangui, central African Republic. J. Antimicrob. Chemother., 51: 192-194.

Haihong, L., Y. Wang, G. Wang, Q. Xing and L. Shao et al., 2015. The prevalence of Escherichia coli strains with extended spectrum beta-lactamases isolated in China. Front Microbiol, 6: 1-5.

Inês, L., T. Raposo, A. Rodrigues and A. Almeida, 2013. Frequency and antimicrobial resistance patterns of bacteria implicated in community urinary tract infections: A ten-year surveillance study (2000-2009). BMC Infect Dis., 13: 1-14.

Iraj, S., M.R. Arabestani, A. Rahimbakhsh, Z. Karimitabar and M.Y. Alikhani, 2015. Dissemination of extendedspectrum $\beta$-lactamases and quinolone resistance genes among clinical isolates of uropathogenic Escherichia coli in children. Jundishapur J. Microbiol., 8: e19184-e19184.

Işıkgöz, T.M., H. Pullukçu, O.R. Sipahi, T. Yamazhan and S. Ulusoy, 2012. Nitrofurantoin in the treatment of extended-spectrum betalactamase- producing Escherichia coli related lower urinary tract infection. Int. J. Antimicrob Agents, 40: 554-556.

Israa, A.J.I., R.M. Al-Shwaikh and M.I. Ismaeil, 2014. Virulence and antimicrobial resistance of Escherichia coli isolated from Tigris River and children diarrhea. Infect Drug Resist., 7: 317-322.

Jean-Marie, S., P. Nabeth, J.D. Perrier-Gros-Claude, I. Bahsoun and T. Siby et al., 2007. Antimicrobial Resistance in Outpatient Escherichia coli Urinary Isolates in Dakar, Senegal. J. Infect Dev. Ctries, 3: 263-268.

Kahlmeter, G., 2003a. Prevalence and antimicrobial susceptibility of pathogens in uncomplicated cystitis in Europe. The ECO.SENS study. Int. J. Antimicrob. Agents, 22: 49-52.

Kahlmeter G., 2003b. An international survey of the antimicrobial susceptibility of pathogens from uncomplicated urinary tract infections: The ECOSENS project. J. Antimirob. Chemother., 51: 69-76.

Kahlmeter, G. and H.O. Poulsen, 2012. Antimicrobial susceptibility of Escherichia coli from communityacquired urinary tract infections in Europe: The ECO•SENS study revisited. Int J. Antimicrob. Agents, 39: 45-51.
Kalpana, G., T.M. Hooton, K.G. Naber, B. Wullt and R. Colgan et al., 2011. International clinical practice guidelines for the treatment of acute uncomplicated cystitis and pyelonephritis in women: A 2010 update by the infectious diseases society of America and the European society for microbiology and infectious diseases. Clin. Inf. Dis., 52: e103-e120.

Killgore, K.M., K.L. March and B.J. Guglielmo, 2004. Risk factors for community acquired ciprofloxacinresistant Escherechia coli urinary tract infection. Ann. Pharmacother, 38: 1148-1152.

Grabe, M., R. Bartoletti, T.E.B. Johansen, T. Cai and M. Çek et al., 2015. Guidelines on urological infections. EAU.

Nisel, Y., N. Ağuş, A. Bayram, P. Şamlıoğlu and M.C. Şirin et al., 2016. Antimicrobial susceptibilities of Escherichia coli isolates as agents of community-acquired urinary tract infection (2008-2014). Turk J. Urol., 42: 32-36.

Rajiv, S., D. Kumar and B. Mukherjee, 2013. Bacteriology and antibiotic resistance pattern in community acquired urinary tract infection. Ind. Pediatr., 50: 15-15.

Ribeiro, R., P. Rossi, J.M. Haddad and J.A. Pinotti, 2002. Therapy of uncomplicated urinary tract infections. Int. Urogynecol J. Pelvic Floor Dysfunct, 13: 190-194.

Schilling, J.D., R. Loreenz and S.J. Hultgren, 2002. Effect of trimethoprim-sulfamethoxazole on recurrent bacteriuria and bacterial persistence in mice infected with uropathogenic Escherichia coli. Infect. Immun, 70: 7042-7049.

Temesgen, B., A. Tesfaye, T. Sewunet and H.D. Waktola, 2015. Pseudomonas aeruginosa isolates and their antimicrobial susceptibility pattern among catheterized patients at Jimma University Teaching Hospital, Jimma, Ethiopia. BMC Res. Notes, 8: 488-488.

Urbina, R., V. Prado and E. Canelo, 1989. Trimethoprim resistance in enterobacteria isolated in Chile. J. Antimicrob Chemother, 23: 143-149.

Wasseem, R., R. Colodner, B. Chazan, M. Elias and R. Raz, 2007. Ten years surveillance of antimicrobial susceptibility of community-acquired Escherichia coli and other uropathogens in Northern Israel (1995-2005). IMAJ, 9: 803-805.

WHO, 2001a. Global strategy for containment of antimicrobial resistance.

WHO, 2001b. Interventions and strategies to improve the use of antimicrobials in developing countries. Rev. Drug Manag. Program.

WHO, 2014. Antimicrobial resistance Global report on surveillance.

Wylie, B.A and H.J. Koornhof, 1989. Trimethoprim resistance in gram negative bacteria isolated in South Africa. J. Antimirob. Chemother, 24: 973-982. 